\title{
Introducción al Método del Sr. Concha
}

Andté Gide comentaba cierta vez en su Joumal (octubre 10, 1918) el recurso polémico favorito de Chesterton: inventar una teoría absurda, atribuírsela a algún crítico anónimo, y luego aniquilarla victoriosamente. Aunque oficiante de otra capilla, el Sr. Concha practica una variante, no menos victoriosa, de ese recurso: la reducción caricaturesca de algún punto de vista ajeno, la aniquilación total de esa caricatura. Aunque sería fácil recordar el dicho célebre ("Los muertos que vos matáis, gozan de buena salud"), el hecho de que la dirección de la Revista Iberoamericand haya decidido dar cabida a las fantasías del Sr. Concha, obliga a una respuesta más detenida.

En un lugar de su pedestre trabajo el Sr. Concha se refiere a algunos puntos de vista de mi libro sobre Pablo Neruda, El viajero inmóvil (Buenos Aires, 1966), sobre las relaciones entre el poeta y su padre.

En la reducción jibárica que practica el Sr. Concha sobre esos puntos de vista, yo habría indicado en tres lugares esa relación:

--página 29: comentario a un poema del Memorial de Isla Negra (poema que el Sr. Concha no transcribe aunque sí transcribe un pedacito de mi comentario);

-página 34: comentario a una reminiscencia infantil de Neruda sobre cómo su padre recibió su primer poema (tampoco transcribe el Sr. Concha el texto de Neruda; también transcribe sólo un pedacito de mi comentario);

- - página 40: comentario al significado simbólico del uso que da Neruda en su bohemia de Santiago a una capa ferroviaria que le había obsequiado su padre (aquí el Sr. Concha se supera: no transcribe ni siquiera un pedacito de mi comentario, lo que no le impide refutarlo; tampoco indica la página de mi libro para que el lector no pueda localizar el pasaje original).

Esta reducción caricaturesca, este jugar con los textos, recortarlos de su contexto, suprimir las reveladoras citas de Neruda, le permite al St. Concha condenar en bloque mis puntos de vista. Un repaso dete- 
nido de lo que realmente digo en mi libro se impone si el lector de la Revista Iberoamericana, y su digna Dirección, no van a ser víctimas de los métodos críticos del. Sr. Concha.

En primer lugar, en no menos de doce lugares (no sólo en los tres caricaturizados por el St. Concha) hago referencia en mi libro a las re. laciones de Neruda con su padre, tan importantes para la comprensión profunda de su personalidad y de su poesía. Los enumero:

-página 16: se esboza aquí una interpretación general: Debido a la hostilidad del padre, que no quería que el niño fuese poeta, Neruda debe inventarse un seudónimo. En vez de firmar sus versos con sa verdadero nombre (Ricardo Neftalí Reyes) los firmará con el seudónimo de Pablo Neruda, que a partir de diciembre 28, 1946, se convertirá en nombre legal del poeta. También se señala allí que

en el Canto general ha quedado una huella de su ambivalencia ante el apellido paterno, el suyo hasta 1946. Reyes aparece un par de veces en una lista de execrados nombres de conquistadores, de incendiarios rapaces, violadores de América. Pero también aparece más adelante en otro poema del mismo libro como nombre de pueblo, oprimido y explotado por los capitalistas locales o extranjeros.

Nada dice el Sr. Concha de este cambio de nombre ni de la circunstancia de que Reyes sea un apellido ambivalente en sus poemas;

-página 26: se transcriben unos versos de Crepusculario, el primer libro de Neruda (1923), que comienzan:

Padre, tus ojos nada pueden.

Nada dice el Sr. Concha de estos versos en su articulo.

-página 27: se transcriben unos versos del Canto general (1950) en que Neruda vuelve a referirse a su padre:

y la barba dorada de mi padre saliendo hacia la majestad de los ferrocarriles,

versos que asocian no sólo la imagen del padre al ferrocarril (el padre era obrero ferroviatio) sino que subrayan su barba dorada, de español. Nada dice el Sr. Concha de esta cita; 
-página 28-29: se transcribe un largo pasaje del Memorial do Isla Negra (1964), en que Neruda describe a su padre en estos tétminos:

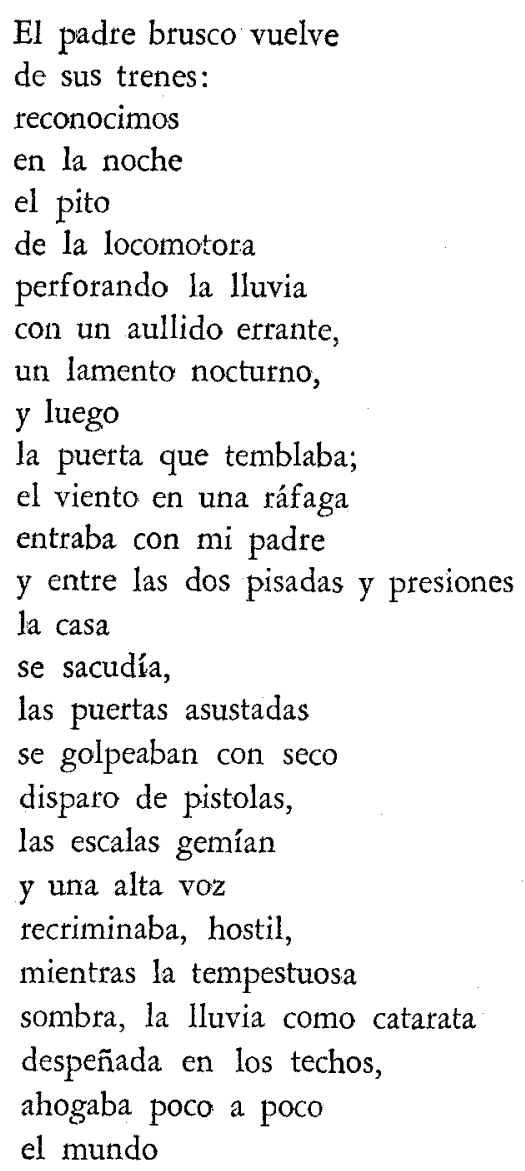

y no se oía nada más que el viento peleando con la lluvia.

Aunque el Sr. Concha transcribe mi comentario a este pasaje, como no transcribe el texto de Neruda, se evita explicar a su lector que es Neruda, y no el crítico, el que presenta esa imagen aterrorizante, de su padre hostil, llegando en la noche con todo el estrépito de la locomotora y la tormenta. Me echa a mi la culpa de una interpretación que el poeta, a los sesenta años, y en el libro autobiográfico que escribe 
para celebrarse, presenta como fidedigna. Curioso método el del St. Concha;

-página 30-32: se comenta una página en que Neruda evoca un episodio de infancia, cuando le hacen beber una copa de sangre de cordero. Ese texto, uno de los más reveladores que ha escrito, no sólo describe su horror sino que lo vincula con un episodio posterior: la visita al cementerio donde está enterrado su padre.

Cito un fragmento de "La copa de sangre", que está reproducido en la página 31 de mi libro:

Entro en un patio, voy vestido de negro, tengo corbata de poeta, mis tíos están allí todos reunidos, son todos inmensos, debajo del árbol guitarras y cuchillos, cantos que rápidamente entrecorta el áspero vino. $\mathrm{Y}$ entonces abren la garganta de un cordero palpi* tante, y una copa abrasadora de sangre me llevan a la boca, entce disparos y cantos, y me siento agonizar como al cordero, y quiero llegar a ser centauro, y, pálido, indeciso, perdido en la desierta infancia, levanto y bebo la copa de sangre.

Si este pasaje es notable por lo que simboliza del rito de iniciación en la edad del hombre, no menos notable ( $y$ terriblemente revelador) es el siguiente, que encadena con el anterior, después de un punto $y$ aparte:

Hace poco murió mi padre, acontecimiento estrictamente laico, $y$ sin embargo algo religiosamente funeral ha sucedido en su tum$\mathrm{ba}$, y éste es el momento de revelarlo. Algunas semanas después mi madre según el diario y temible lenguaje fallecía también, y para que descansaran juntos trasladamos de nicho al caballero muerto. Fuimos a mediodía con mi hermano y alguno de los ferroviarios amigos del difunto, hicimos abrir el nicho ya sellado y sedimentado, y sacamos la urna, pero ya llena de hongos, y sobie ella una palma con flores negras y extinguidas, la humedad de la zona había partido el ataúd y al bajarlo a si sitio, ay, sin crezr lo que veía, vimos bajar de él cantidades de agua, cantidades como interminables litros que caían de adentro de él, de su sustancia.

Pero todo se explica, esta agua trágica era lluvia, lluvia tal vez de un solo día, de una sola hora tal vez de nuestro austral invierno, y esta lluvia había atravesado techos y balaustradas, ladrillos y otros materiales y otros muertos hasta llegar a la tumba de mi deudo. Ahora bien, esta agua terrible, esta agua salida 
de un imposible, insondable, extraordinario escondite, para mostrarme a mí su torrencial secreto, esta agua original y temible me advertía otra vez con su misterioso derrame mi conexión interminable con una determinada vida, región y muerte.

El texto completo de "La copa de sangre", se reproduce en las páginas citadas de mi libro sobre Neruda para documentar su visión de "la magia y los terrores imborrables de la infancia" y para mostrar a qué tipo de imaginería simbólica ha ido reduciendo el poeta la imagen de su padre. Naturalmente, nada dice el Sr. Concha en su estudio de esta interpretación aútobiográfica;

-páginas 32-34: se transcribe y comenta un fragmento de las $\mathrm{Me}^{-}$ marias de Neruda (publicadas en la revista brasileña $O$ Cruzeiro, en 1962), en que el poeta cuenta la primera reacción de su padre a la noticia de que el niño quiere ser poeta: Después de tomar con mano dis'raída el poema que le alarga el niño, el padre

distraídamente lo leyó, distraídamente me lo devolvió, diciéndome: ¿De dónde lo copiaste?

Y siguió conversando en voz baja con mi madre, de sus importantes y remotos asuntos.

Me parece recordar que así nació mi primer poema y que así recibí la primera muestra distraida de la crítica lieraria.

También se transcriben en las páginas citadas de mi libro, las confidencias que una vieja tía de Neruda, doña Glasfira, hizo a Margarita Aguirre y que ésta reproduce en su Genio y figura de Pablo Neruda (Buenos Aires, 1964):

sus primeras poesías le costaron azotes, pero él siguió incólume hacia la meta que le iba a dar celebridad. Nosotros no supimos estimularlo. Nos hubiera gustado más que siguiera una profesión liberal, que ganara dinero. Pero el se fugó por entero a su inspiración tan honda. Ningún interés humano puede desviarlo.

Por esta confidencia es posible conjeturar que Neruda recibió algo más sólido y hostil que la distracción de su padre como respuesta a su vocación de poeta. Que tuvo que imponer su voluntad contra el desprecio y el castigo, que debió ampararse en un seudónimo para poder seguir publicando sus versos, En mi libro se advierte al lector: 
Sin duda el proceso que aquí se sintetiza ha sido más largo y complejo, con etapas intermediarias en que la indiferencia de José del Carmen por los versos de su hijo habrá dado paso a una sonrisa tolerante; sólo después, cuando comprendió que el muchacho realmente quería ser poeta, la tolerancia se convirtió en firme oposición. Cuando es indudable que el muchacho ha de ser sobre todo poeta, el duro hombre rubio de bjos dulces deja las sontisas y las amenazas y hasta castiga. De ese terror y ese desafio a la figura paterna, de esa rebeldía y de esa convicción de la fatalidar de su destino, nace Pablo Neruda, el poeta. Su padre fue su primer crítico y marcó para siempre la relación del muchacho, del joven, del hombre, con futuros críticos.

Inútil subrayar que de toda esta documentación, el Sr. Concha sóno cita las dos illtimas frases de mi comentario. Al omitir tanto el testimonio de Neruda sobre la recepción de su primer poema, como el de doña Glasfira sobre los azotes, el Sr. Concha se permite una fácil victoria imaginaria;

-página 40: se comenta el uso que da Neruda a la capa de ferrisviario que le dio su padre al partir a la capital, y se transcribe el pasaje autobiográfico correspondiente:

La Empresa de Ferrocarriles proveía a mi padre, para sus labores a la interperie, de una capa de paño gris que nunca usó. Yo la destiné a la Poesía. Tres o cuatro poetas comenzaron también a usar capas parecidas, o la mía, que cambiaba de mano.

Esta prenda provocaba la furia de las buenas gentes y de al. gunos no $\tan$ buenos.

Aquí el Sr. Concha se sobrepasa: sin citar el texto de Neruda, $n$ citar tampoco ninguno mio en apoyo de sus afirmaciones, me atribuye una interpretación que no hago y que si Neruda hace. Yo me limito a citar al poeta, sin agregar un solo comentario;

-página 44: se comenta el hecho de que para pagar la primera edición de Crepusculario, Neruda haya vendido sus muebles y un reloj que le había regalado su padre:

El sacrificio del reloj es simbólico en más de un sentido si se tiene en cuenta no sólo la resistencia de su padre a aceptar la poesía del joven, sino también lo que el reloj significa como el símbolo de la posesión viril del tiempo. Así como había metamorfoseado 
la capa de ferroviario del padre en capa de la poesía, ahora convierte el reloj en libro de versos. Curiosos y metafóricos desquites.

Nada dice el Sr. Concha de este episodio del reloj, a pesar de que es aquí donde yo también hablo del significado simbólico de la capa. Pero el Sr. Concha no tiene interés en discutir sino los temas que su caricatura le autoriza:

-página 66: se hace una referencia a una carta que el padre es. cribe a Neruda durante la estancia de éste en el Oriente. En una carta del poeia a su amigo Eandi, aquél anota que es la "primera carta en casi tres años". Nada dice el Sr. Concha de esta carta, ni del posible origen del silencio del padre;

-página 97: se comenta la muerte del padre y se refiere una anécdota, transmitida por Margarita Aguirre en su biografía, que ese mismo día Neruda escribe el primer poema del Canto General; Nada dice el Sr. Concha de estie episodio;

-página 220: se comenta el poema, "Estatuto del vino", de Residencid en la tierra, y se afirma:

También se canta allí a los hombres del vino, esos chilen'os dei Sur que el poeta conoció de niño y de los que fue paradigma su propio padre, el duro y lejano ferroviario, esos hombres que fueron sus compañeros en la lejana bohemia de Santiago.

Nada dice el Sr. Concba de este pasaje que, infortunadamente, no parece encajar en su esquema dialéctico;

-página 236: se comenta el origen verdadero del Canto general y se escribe.

El libro nace el día de la muerte de José del Carmen Reyes, el duro ferroviario que nunca quiso que su hijo fuera poeta. En Ia noche de mayo 7 de 1938, el poeta se encierra en el escritorio de la casa del doctor Manuel Martín, pide papel y escribe el primer poema de lo que será (diez y hasta once años más tarde) el Canto general. A la mañana siguiente (ha contado el doctor Mar'ín a Margarita Aguirre), el dueño de casa encontró lo que había escrito la noche antes el poeta. Es un fragmento del libro II del Canto general, "Los conquistadores", en que evoca al duro Almagro. 
En mi libro se transcribe el poema entero, que muestra a Almagro, como un ave rapaz, arrojando la mirada ávida (como de macho en celo) sobre la tierra chilena. Nada dice el Sr. Concha de este episodio ni de mi comentario.

Para concluir: Basado en los documen'os autobiográficos del poeta (que reiteradamente señalan su hostilidad que existía entre él y su padre), apoyado en las confidencias de familiares y amigos, citando escrupulosamente todos los textos a mi alcance, he presentado una interpretación que ahora el Sr. Concha se propone refutar por el métocio chestertonian'o de la caricatura y la demolición imaginaria. Estoy dis. puesto a creer que mi interpretación es insuficiente, has a errónea. Pero no será el St. Concha con sus omisiones estratégicas y sus citas truncas el que me habrá de convencer. El Sr. Concha tiene todaví mucho camino que recorrer antes de poder sacar ninguna conclusión sobre mis puntos de vista.

Debe, ante todo, analizarlos uno por uno (doce y no tres lugares), restaurando las citas omitidas de Neruda y el contexto completo de las opiniones que me atribuye; debe traer otros materiales que contradigan mis documentos y puntos de vista; debe, en fin, leer a Neruda en pro. fundidad, lo que no parece haber siquiera empezado a hacer en este artículo. Sólo entonces se hará acreedor a que su texto sea publicado en la Revista Iberoamericana, y que sea leído con alguna seriedad. Mientras tanto su trabajo sólo sirve para documentar la mediocridad de un método ni siquiera polémico.

Yale University.

EMIR RoDRíGUEZ MONEGAL 